\title{
COMPARAÇÃO DO PADRÃO DE FINALIZAÇÃO DE PRATICANTES DE FUTSAL DE DIFERENTES IDADES
}

Gibson Moreira Praça, Universidade Federal de Minas Gerais - UFMG, Minas Gerais Brasil

Fabiola de Araújo Cabral, Universidade Federal de Minas Gerais - UFMG, Minas Gerais - Brasil

Pablo Juan Greco, Universidade Federal de Minas Gerais - UFMG, Minas Gerais Brasil

\section{RESUMO}

Objetivou-se comparar três parâmetros relacionados à finalização - situação, resultado e setor - entre praticantes de Futsal das categorias sub-13, sub-15, sub-17 e sub-20. Coletaram-se jogos durante competições escolares em Minas Gerais no ano de 2010. Nas categorias Sub-15, Sub-17 e Sub-20, a situação mais frequente de finalização foi jogo organizado, enquanto na categoria Sub-13 o lateral ofensivo foi a situação com maior incidência de finalização. Para todas categorias houve maior incidência de finalizações em regiões próximas ao gol, contudo para a categoria Sub-13 registrou-se uma maior incidência nos setores laterais da intermediária ofensiva. Observou-se diferença significativa no número de gols das categorias Sub-13 e Sub-20 - maior - que o apresentado nas demais. Contudo, como o total de finalizações na categoria Sub-20 foi significativamente inferior à categoria Sub-13, pode-se apontar que a categoria de maior idade apresentou maior efetividade nas finalizações. Houve diferenças no padrão de finalização das equipes em diferentes idades, resultado que permite aos treinadores possuir conhecimento acerca da proficiência com que os jogadores e a equipe realizam diferentes tarefas e assim aferir a congruência da sua prestação em relação aos modelos de jogo e treino preconizados.

Palavras-Chave: Futsal; Análise de jogo; Finalização.

\section{COMPARISION OF THE SHOOT ON GOAL PATTERN IN INDOOR SOCCER ATHLETES OF DIFFERENT AGES}

\begin{abstract}
The aim of the study was compare three parameters related to the finalization - situation, result and sector - between Indoor Soccer players for Under-13 (U-13), Under-15 (U-15), Under-17 (U-17) and Under-20 (U-20) ages. The samples was collected during scholar Indoor Soccer competitions in Minas Gerais on the 2010 year. The results showed that the most frequent situation of finalization was the Organized Game on the U-15, U-17 and U20 ages, while the Offensive Throw-in was the most frequent situation on the U-13. It was observed that the sectors closer to the goal was the most frequent for the shoots in all ages. Besides this, there was a significance difference between the U-13/U-20 which greater number of goals, and U-15/U-17, with less goals scored. However, the U-13 presented
\end{abstract}


more finalizations than the U-20, what reveal that the U-20 was more effective than the U13. There were differences between different ages in the finalization pattern, that allows coaches to have knowledge about the player's and team's proficiency for perform different tasks and thus assess the consistency of their performance in relation to recommend game modeling and training.

Key-Words: Indoor soccer; Match analysis; Shoots on goal.

\section{COMPARACIÓN DE LOS PATRONES DE FINALIZACIÓN DE PRACTICANTES DE FUTSAL DE EDADES DIFERENTES}

\section{RESUMEN}

El objetivo consistió em evaluar tres parámetros relacionados con la finalización del juego: situación, resultado y sector - entre practicantes de Futsal de las categorías sub-13, sub15, sub-17 y sub-20. Fueron estudiados juegos de las competiciones escolares en el estado de Minas Gerais en el año de 2010. En las categorías Sub-15, Sub-17 e Sub-20, la situación más frecuente de finalización fue el "Juego Organizado" por su vez en la categoría Sub-13 el saque "Lateral Ofensivo" fue la situación con mayor incidencia de finalización. Para todas las categorías se presentó mayor frecuencia de finalizaciones en las regiones próximas a la meta, más en la categoría Sub-13 se registró una mayor incidencia en los sectores laterales del espacio intermediario ofensivo. Se observó diferencia significativa en el número de goles de las categorías Sub-13 y Sub-20 - mayor - que en todas las otras. No obstante, con el total de finalizaciones en la categoría Sub-20 fue significativamente inferior al de la categoría Sub-13, se puede mencionar que la categoría de mayor edad presentó mayor efectividad en las finalizaciones. Se evidenciaron diferencias en el patrón de finalización de los equipos en diferentes edades, resultado que permite a los entrenadores adquirir conocimiento sobre la eficiencia con que los jugadores y el equipo realizan diferentes tareas y así conferir la congruencia de su realización en relación a los modelos de juego y de entrenamiento preconizados.

Palabras-Clave: Futsal; Análisis de juego; Finalización. 


\section{INTRODUÇÃO}

O futsal é um jogo de invasão caracterizado pela participação simultânea de duas equipes em um espaço comum em que apresentam-se particularidades que solicitam um forte apelo à inteligência dos jogadores. ${ }^{1}$ As ações no futsal realizam-se com pressão espaço-tempo, bem como relativizadas pelo contexto situacional (relação entre o placar do jogo, o tempo restante de jogo, a situação especifica de jogo-igualdade numérica, superioridade etc. e os objetivos definidos para o jogo), o que eleva as solicitações de velocidade e acurácia da tomada de decisão (tática). Os aspectos velocidade e precisão constituem-se em parâmetros fundamentais para um desempenho de alto nível, não somente no futsal, bem como nos esportes que compõem o conjunto dos denominados Jogos Esportivos Coletivos. ${ }^{2-3}$

Nesta modalidade, bem como nos demais Jogos Esportivos Coletivos (JEC), as relações de oposição e cooperação condicionam as ações dos atletas. ${ }^{4}$ Tal característica faz com que o jogo apresente variações táticas de realização, ou seja, diferentes formas de tomadas de decisão e ação coletivas e/ou individuais, visando o alcance da meta adversária. ${ }^{5}$

O estudo do comportamento de jogadores em uma partida na perspectiva da metodologia observacional $^{6}$ a qual se constitui como uma das opções de estudo científico do comportamento humano $^{7}$ não é recente. Na realidade, a observação e análise da performance de atletas, e de equipes, evidencia-se há muitos anos sob diversos nomes (observação de jogo, análise de jogo e análise notacional). ${ }^{8} \mathrm{~A}$ análise de jogo revela-se como uma importante ferramenta na identificação de variáveis de performance tanto no futsal quanto nos demais Jogos Esportivos Coletivo. ${ }^{9}$ A mesma contribui para o entendimento das condições que concorrem para o sucesso nos jogos desportivos ${ }^{8}$ e a consequente planificação dos processos de ensino.

Entender as dinâmicas do jogo e da equipe contribui na elaboração de tarefas apropriadas na prática esportiva, seja recorrendo-se a variação das situações-problema com objetivos específicos de aprendizado, assim como promover comportamentos auto adaptativos para os jogadores e equipes, ${ }^{9}$ seja na estruturação das atividades na forma de jogos idealizados para modelar o comportamento tático dos atletas. Além disso, com a evolução do futsal e o Conexões: revista da Faculdade de Educação Física da UNICAMP, Campinas, v. 11, n. 4, p. 24-44, out./dez. 2013. ISSN: $1983-9030$ 
aumento das exigências na qualidade de jogo, solicita-se que treinadores tenham informações concretas a que possam recorrer para melhorar a ação das suas equipes e dos seus jogadores. ${ }^{10}$

No futsal, evidenciam-se duas fases dentro de um jogo: a ofensiva e a defensiva, além das transições entre uma e outra (contra-ataque e retorno defensivo). Nestas fases, coexistem conceitos táticos específicos para cada uma. A tática ofensiva inicia-se quando a equipe está com a posse de bola ${ }^{2}$ e fundamenta-se em três princípios: conservar da posse de bola (para evitar que a equipe adversária o ataque); promover o desequilíbrio da defesa adversária (para criar espaços, para assim progredir até a meta adversária, gol); e finalizar ao gol. ${ }^{11-14}$

A fase ofensiva do jogo de futsal é objeto de estudos e pesquisas. ${ }^{15-17}$ Contudo, o planejamento dos processos de ensino-aprendizagem-treinamento, solicita o conhecimento das particularidades presentes nas diferentes categorias e faixas de rendimento a fim de adequar as escolhas do treinador à necessidade do processo de formação dos futuros atletas. Nessa direção poucos tem sido os estudos relacionados até hoje no futsal. ${ }^{18}$

Com o intuito de contribuir no entendimento das diferenças estabelecidas entre o desempenho de praticantes de futsal de diferentes idades, o objetivo deste trabalho consiste em comparar três parâmetros relacionados à finalização - situação, resultado e setor - entre praticantes de futsal das categorias sub-13, sub-15, sub-17 e sub-20.

\section{MATERIAIS E MÉTODOS}

\section{Amostra}

No marco do projeto de pesquisa intitulado "Análise Tática nos Jogos Esportivos Coletivos nas Categorias de Base de Minas Gerais", realizado com apoio da Fundação de Amparo à Pesquisa do estado de Minas Gerais - FAPEMIG - (Processo No: APQ-01254-09), foram filmados 59 jogos (10 sub-13, 21 sub-15, 19 sub-17 e 9 sub-20) durante o Campeonato Metropolitano Escolar de Futsal (organizado pela Federação de Esporte Escolar de Minas Gerais) durante o ano de 2010.

Conexões: revista da Faculdade de Educação Física da UNICAMP, Campinas, v. 11, n. 4, p. 24-44, out./dez. 2013. 


\section{Procedimentos de coleta de dados}

Os jogos foram filmados com câmeras posicionadas na lateral da quadra, nas proximidades da linha central e no local mais alto possível da arquibancada, de forma a obter o maior ângulo de filmagem possível para a maior parte da quadra.

\section{Instrumento}

O instrumento utilizado para a codificação das ações de finalização apoiou-se nos critérios de Silva, ${ }^{2}$ o qual visa avaliar as ações das equipes em situação real de jogo. Os critérios abordam três indicadores de jogo: situação, setor e resultado da finalização. $\mathrm{O}$ indicador "situação" se compõe de seis parâmetros: jogo organizado, contra-ataque, lateral (ofensivo e defensivo), escanteio, falta e bola roubada. O indicador de jogo "setor" aborda dez parâmetros que determinam o local da finalização na quadra ofensiva que é dividida em nove setores imaginários, sendo o décimo setor a meia quadra defensiva (Figura 1). Por fim, o terceiro indicador de jogo "resultado da finalização" tem como parâmetros: gol, trave, defendida pelo goleiro, rebatida pelo goleiro, interceptada pela defesa e fora.

\section{SETORES/FIIIALIZAÇAO}

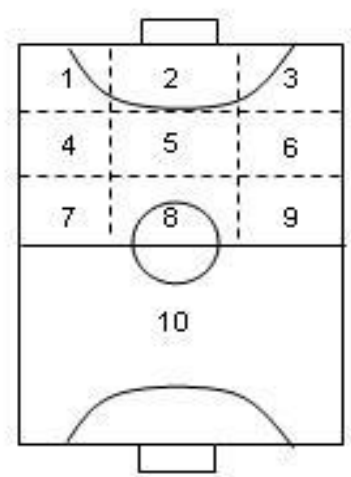

Figura 1: Distribuição dos setores de finalização na quadra de futsal.

\section{Análise dos dados}

Para a análise utilizaram-se os Softwares SPSS 20.0 e XLSTAT. Procedeu-se incialmente a aplicar o teste de Shapiro-Wilk para análise da distribuição dos dados. Na sequencia optouse por recorrer a procedimentos não paramétricos, com a utilização do Median Test (para 
comparação das medianas dos valores entre os grupos) e do teste de correlação de Spearman.

\section{RESULTADOS}

No total das observações dos 59 jogos, registraram-se 2548 finalizações, distribuídas da seguinte forma:

Quadro 1 - Distribuição das finalizações entre as categorias

\begin{tabular}{lrrrr}
\hline & Sub-13 & Sub-15 & Sub-17 & Sub-20 \\
\hline Total & 569 & 887 & 779 & 313 \\
Média & 56,90 & 42,24 & 41,00 & 34,78
\end{tabular}

Como o total de jogos observados de cada categoria não foi uniforme, esperavam-se diferenças nos totais de finalizações para cada idade. Além disso, observou-se que a categoria Sub-13 apresentou a maior média de finalizações por jogo, ao passo que a categoria Sub-20 apresentou menor média de finalizações, revelando uma tendência de redução na ocorrência dessa ação nos jogos observados com o aumento da idade dos praticantes.

O Gráfico 1 apresenta os resultados para a situação da finalização. Observa-se que a categoria sub-13 apresentou valores significativamente maiores do que pelo menos uma das demais categorias para as situações de Lateral Defensivo* $(p=0,026)$, Lateral Ofensivo ${ }^{\dagger}$ $(p=0,0001)$, Escanteio $(p=0,005)$, Falta $(p=0,015)$ e Bola Roubada $(p=0,001)$, enquanto o sub-17 apresentou valores significativamente maiores do que o sub-13 na situação Jogo Organizado $(\mathrm{p}=0,0001)$.

\footnotetext{
* Cobrança de Lateral realizada na metade defensiva da quadra de jogo

† Cobrança de lateral realizada na metade ofensiva da quadra de jogo

Conexões: revista da Faculdade de Educação Física da UNICAMP, Campinas, v. 11, n. 4, p. 24-44, out./dez. 2013.

ISSN: 1983-9030
} 

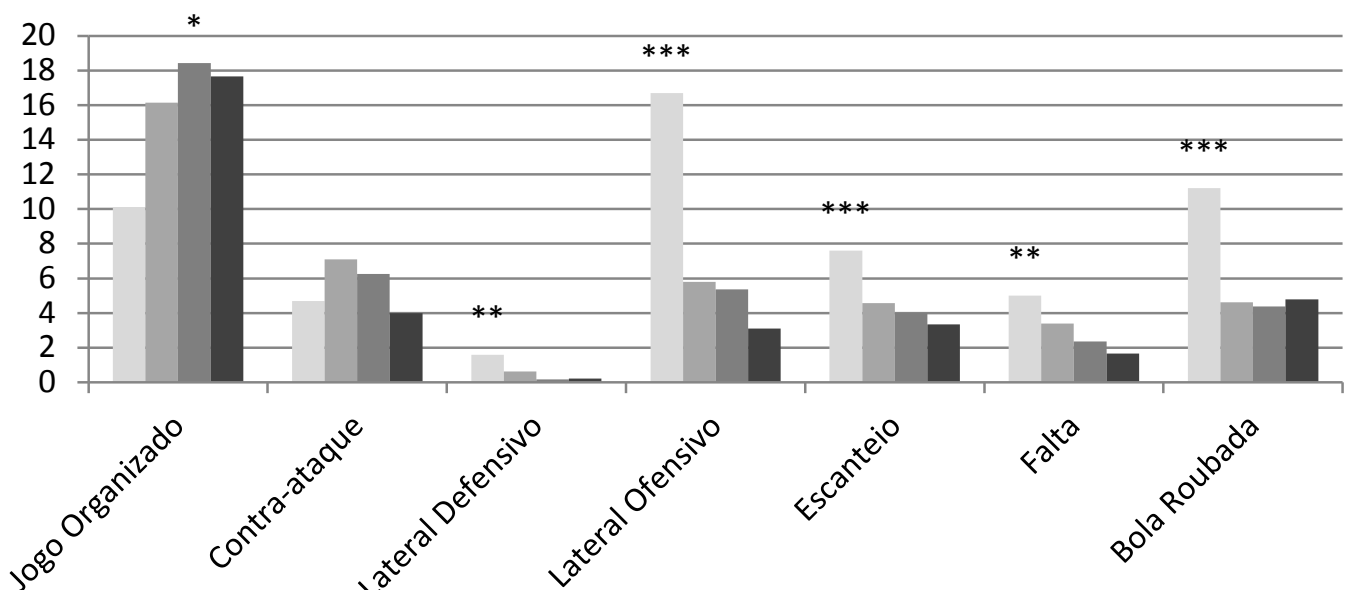

- Sub-20

Gráfico 1: Comparação dos valores para as diferentes situações entre as quatro categorias.

Legenda:

* Diferença significativa para a categoria de menor valor na mesma situação $(\mathrm{p}<0,05)$

** Diferença significativa para as duas categorias com menor valor na mesma situação $(\mathrm{p}<0,05)$

*** Diferença significativa para as três categorias na mesma situação $(\mathrm{p}<0,05)$

O Gráfico 2 apresenta o comparativo entre finalizações que ocorreram a partir de situações de bola parada (lateral, escanteio e falta) e de bola em jogo (jogo organizado, contra-ataque e bola roubada). É possível verificar que nas categorias sub-15, sub-17 e sub-20 há significativamente mais finalizações advindas de bolas em jogo do que de bolas paradas ( $\mathrm{p}=0,0001$ e $\mathrm{p}=0,0001$, respectivamente), situação que não ocorre no sub-13. Também é possível visualizar que o total de finalizações a partir de bolas paradas é significativamente maior na categoria sub-13 do que nas demais ( $\mathrm{p}=0,007$ para o sub-15, $\mathrm{p}=0,0001$ para o sub-17 e p<0,0001 para o sub-20).

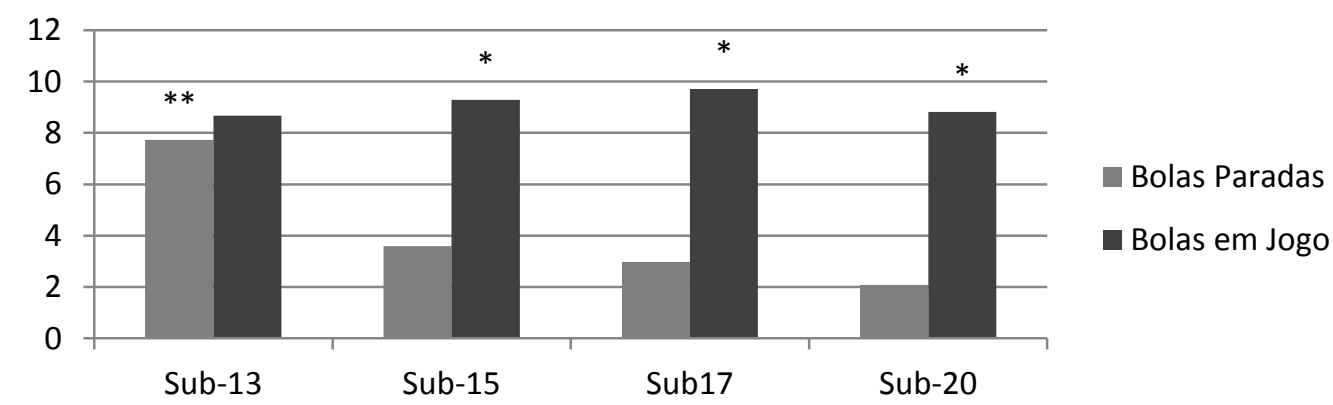

Gráfico 2 - Comparação das finalizações a partir de bolas paradas e em jogo nas quatro categorias.

Legenda:

* Diferença significativa na mesma categoria $(\mathrm{p}<0,05)$

** Diferença significativa para a mesma situação - bola parada ou em jogo - para as demais categorias $(\mathrm{p}<0,05)$. 
No que tange aos setores da quadra onde ocorreram as finalizações, o Gráfico 3 abaixo apresenta os resultados. Observa-se que o sub-13 finaliza mais da região intermediária ofensiva da quadra (setores 4,5 e 6 ) em comparação às demais categorias, enquanto o sub15 também possui maiores valores para as regiões 4 e 6, mas também valor significativamente maior no setor 9 (embora ainda seja o segundo menor valor dentre todos os setores para esta categoria). Nos demais setores da quadra não foram encontradas diferenças significativas.

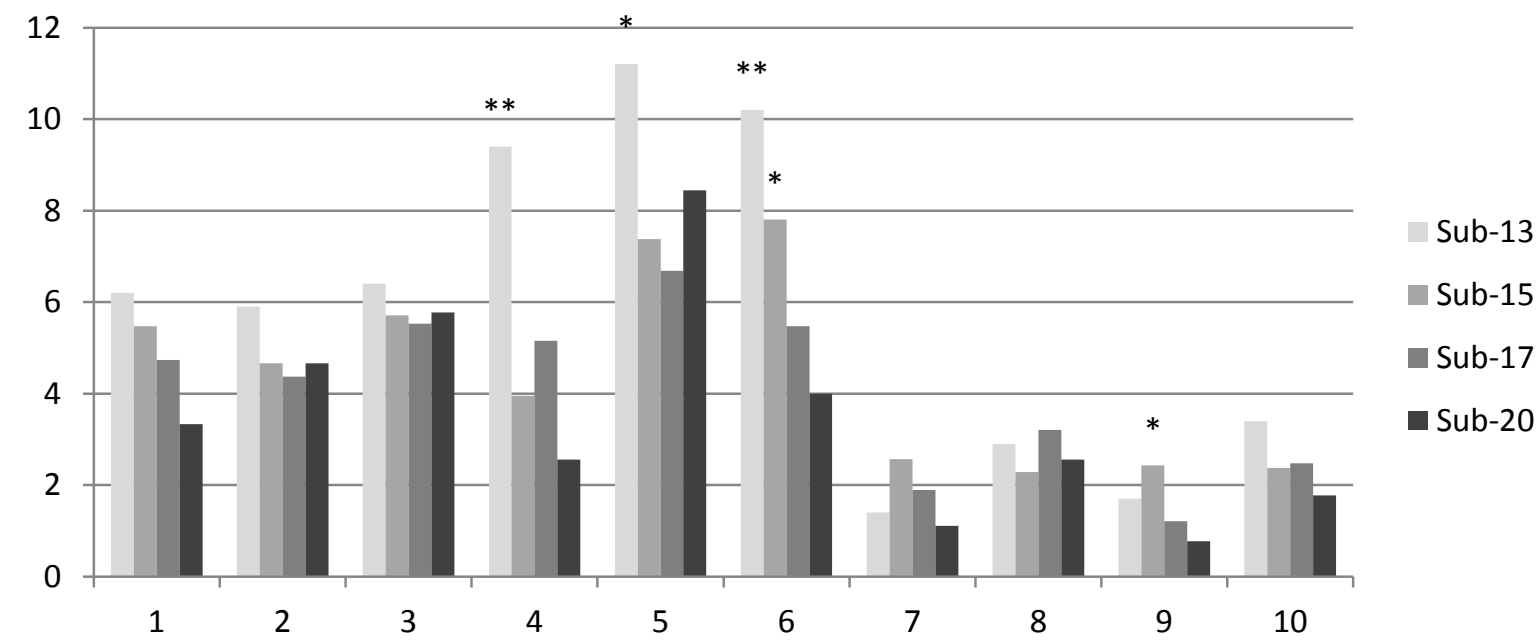

Gráfico 3 - Comparação dos setores de finalização entre as categorias.

Legenda:

* Diferença significativa para a categoria de menor valor $\mathrm{p}<0,05$

** Diferença significativa para as duas categorias de menor valor $\mathrm{p}<0,05$

Para o terceiro parâmetro do instrumento utilizado, resultado da ação, o Gráfico 4, abaixo, apresenta os dados para as quatro categorias analisadas. Observa-se que em todas as categorias os resultados mais frequentes são: chute fora e bola rebatida pela defesa. Além disso, observa-se que a categoria sub-13 apresentou valores significativamente maiores de bolas rebatidas na defesa em relação à categoria sub-20 (p=0,048) e rebatidas pelo goleiro em relação à categoria sub-20 $(\mathrm{p}=0,04)$ e gols em relação à categoria sub-17 $(\mathrm{p}=0,06)$, enquanto a categoria sub-20 apresentou valores significativamente maiores de gols em relação à categoria sub-17 (p=,079). 


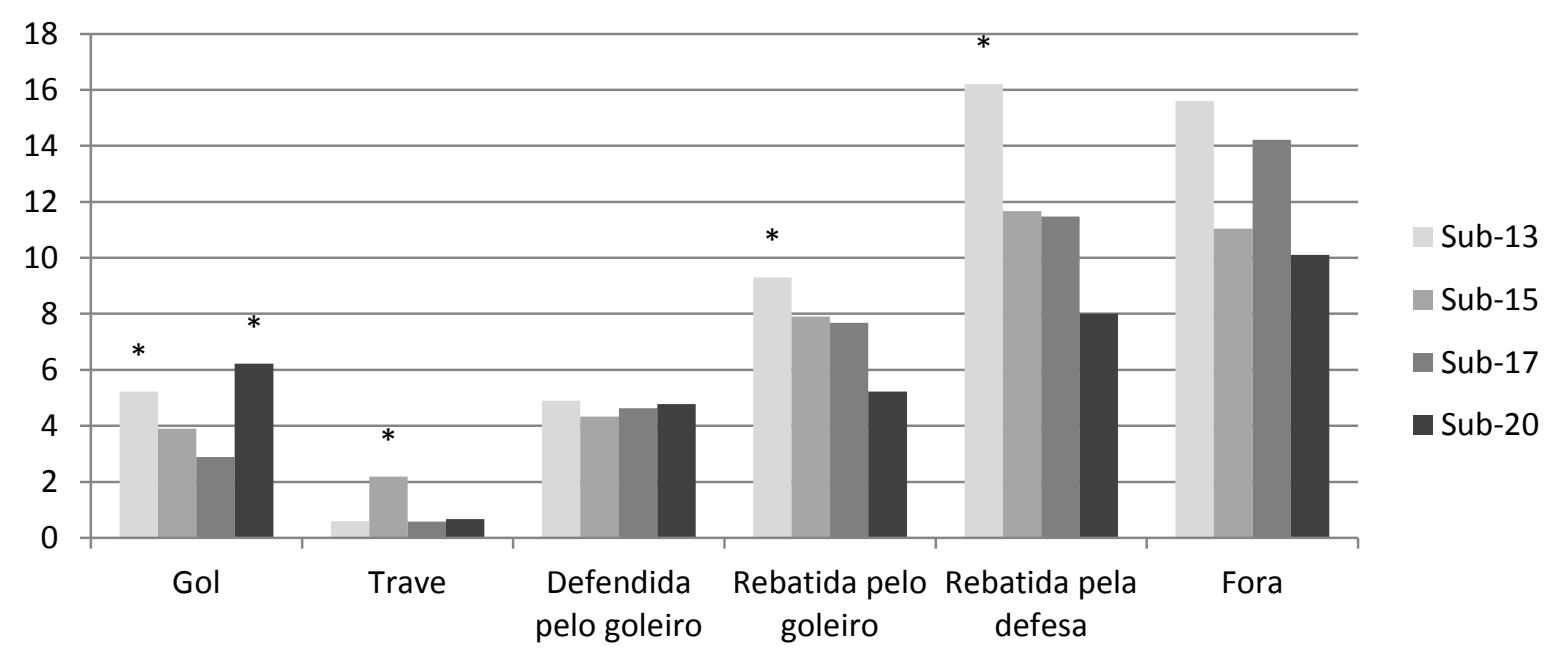

Gráfico 4 - Comparação do resultado da finalização para as quatro categorias.

Legenda:

* Diferença significativa para a categoria com menor valor $(\mathrm{p}<0,1)$.

A seguir, apresentou-se a necessidade de se conhecer si existiria relação entre numero de finalizações e gols marcados. Para isso, procedeu-se a verificar a intensidade da correlação entre a ocorrência de finalizações e a ocorrência de gols marcados pelas equipes. O quadro abaixo apresenta os coeficientes de correlação entre estas duas variáveis para cada uma das categorias. Os valores em negrito representam correlações significativas.

Quadro 2 - Coeficientes de Correlação de Spearman para frequência de finalização e frequência de gols, e os respectivos valores $\mathrm{p}^{\ddagger}$. Valores significativos.

\begin{tabular}{lrl}
\hline & Correlação & p-valor \\
\hline Sub-13 & $-0,162$ & \\
Sub-15 & $\mathbf{0 , 6 6 1}^{\S}$ & $\mathbf{0 , 0 0 1}^{* *}$ \\
Sub-17 & 0,448 & \\
Sub-20 & $\mathbf{0 , 8 5 5}^{\dagger \dagger}$ & $\mathbf{0 , 0 0 6}^{\text {}}$
\end{tabular}

\footnotetext{
$\$$ Valores significativos

$\S$ Valores significativos

** Valores significativos

${ }^{\dagger}$ Valores significativos

\$Valores significativos
}

Conexões: revista da Faculdade de Educação Física da UNICAMP, Campinas, v. 11, n. 4, p. 24-44, out./dez. 2013. 
Conforme observado, a categoria Sub-20 apresentou correlação positiva e elevada entre frequência de finalizações e frequência de gols, indicando que finalizar mais, para as equipes desta categoria, significou marcar mais gols. Por outro lado, na categoria Sub-13, verificou-se correlação negativa baixa entre estas duas variáveis, indicando que finalizar mais, nesta faixa etária, não representa aumento no número de gols das equipes.

O Gráfico 6, a seguir, apresenta a comparação dos valores de finalizações e gols entre as categorias. Destaca-se no gráfico que, a categoria sub-13 apresentou valores maiores no total de finalizações em comparação à categoria sub-20 ( $\mathrm{p}=0,087)$, contudo não foram encontradas diferenças significativas entre estas duas categorias no total de gols, sendo que as duas apresentaram maior quantidade de gols do que as categorias sub-15 e sub-17 $(\mathrm{p}<0,1)$

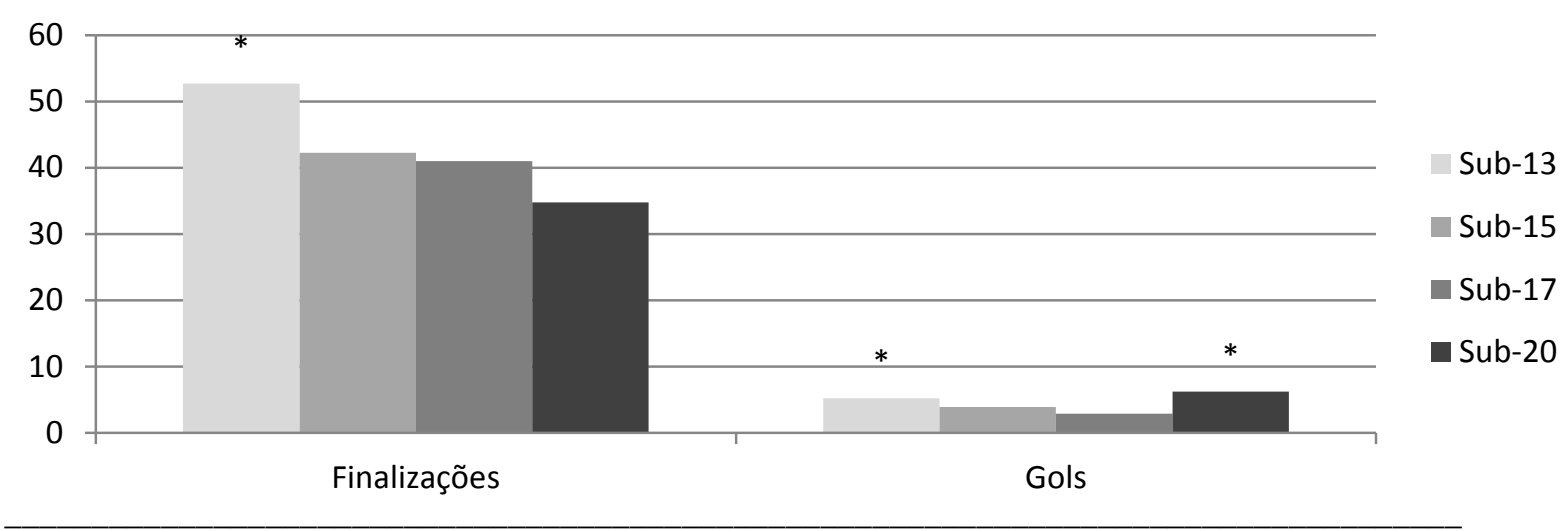

Gráfico 5: Comparação do total de finalizações e gols por jogo entre as quatro categorias Legenda:

* Diferenças significativas para a categoria com menor valor $(\mathrm{p}<0,1)$

\section{DISCUSSÃO}

O presente estudo objetivou analisar, a partir do instrumento proposto por Silva, ${ }^{2}$ o padrão de finalização de equipes de futsal e comparar estes entre quatro diferentes categorias. Observa-se que, com exceção da categoria sub-13, o Jogo Organizado evidencia-se como a principal situação de ocorrência de finalizações, em consonância com outros estudos. ${ }^{17,}$ 1920

Assim, destaca-se a necessidade nos processos de ensino-aprendizado-treinamento da realização de atividades de jogo com pequenas sociedades - como, por exemplo, 3 x 3 nas suas diferentes alternativas de igualdade, superioridade numérica e com uso do curinga - de Conexões: revista da Faculdade de Educação Física da UNICAMP, Campinas, v. 11, n. 4, p. 24-44, out./dez. 2013. ISSN: $1983-9030$ 
forma a potencializar as combinações de passes, o jogo sem bola em espaços reduzidos, a toma de marcação e as coberturas defensivas, permitindo assim a vivência de conteúdos técnico-táticos que contribuem positivamente no desenvolvimento do jogo coletivo. Nestas tarefas, os espaços são explorados e ocupados através de uma linguagem de comunicação comum entre seus participantes. Tal linguagem se orienta em Princípios Táticos - Gerais, Operacionais, Fundamentais e Específicos, ${ }^{4}$ sendo específica para as respectivas fases/momentos do jogo, caracterizadas pelo ataque, a defesa e as transições (defesaataque, ou contra-ataque, e ataque-defesa, ou retorno defensivo). Em cada uma destas fases a relação estabelecida com os Princípios Táticos assume contornos de especificidade, orientada pelas demandas em cada momento do jogo - recuperar a posse de bola/evitar a progressão do adversário na fase defensiva e manter a posse de bola e finalizar ao gol na fase ofensiva. A vivência em situações de jogo reduzido permite que as linguagens sejam compartilhadas pelos participantes, e que sinais relevantes sejam permanentemente percebidos de forma a melhorar o comportamento técnico-tático no jogo formal.

Os problemas táticos no futsal podem ser considerados em três grandes categorias: fazer gol (ou seja, finalizar a gol), evitar o gol e reiniciar o jogo. A primeira categoria engloba quatro sub-problemas táticos: manter a posse de bola, atacar em direção a meta adversária, criar espaço para a definição no ataque e usar o espaço no ataque durante o jogo organizado de forma permitir uma finalização com sucesso. A segunda categoria, da defesa, implica em - evitar o gol - envolve os sub-problemas defender o espaço, defender o gol e recuperar a bola. Contudo, a supervalorização de conteúdos inerentes ao ataque evidenciada na baixa eficiência do processo defensivo das equipes na categoria sub-13, contrastada à eficiência defensiva da categoria sub-20, indica a má distribuição dos conteúdos de treino e o consequente baixo estímulo à solução de problemas táticos por parte dos atletas.

Além disso, evidenciou-se que, dentre as equipes pesquisadas, há, com exceção da categoria sub-13, a preferência por finalizar a partir de situações de Jogo Organizado em comparação a ações de Bola Parada. Acredita-se que, em um Jogo Esportivo Coletivo, criar desequilíbrios na defesa adversária através de movimentações dos jogadores, levando 
assim a marcação e criando espaços para os colegas, passes, dribles ou jogadas ensaiadas, ações características do Jogo Organizado, constituem-se em ferramentas fundamentais no sucesso de estratégias ofensivas. ${ }^{21}$ Contudo, as situações de bola parada, dado o espaço reduzido onde se desenvolve o jogo e a frequência com que estas situações ocorrem, tornam-se, muitas vezes, importantes no desfecho do jogo. ${ }^{22}$

O sucesso de estratégias ofensivas visando desequilíbrios na defesa adversária está associado a uma elevada participação de componentes cognitivos, na medida em que processos bidirecionais de percepção-ação ${ }^{23}$ nas interações pessoa-tarefa-ambiente ${ }^{24}$ que se apresentam no jogo são imprevisíveis, complexas e aleatórias. ${ }^{25}$ Neste ponto, o desenvolvimento destes componentes cognitivos nos processos de ensino-aprendizagemtreinamento facilitariam aos jogadores a busca e seleção de respostas para as situaçõesproblema do jogo. ${ }^{26}$ Assim, atividades com a presença constante de constrangimentos ambientais, que assemelhem a realidade do jogo formal tornam-se conteúdo importante. Nas categorias sub-15, sub-17 e sub-20, fica evidente que a situação de Jogo Organizado foi a principal geradora de oportunidades de finalização, o que indica a capacidade dos atletas em concretizar ações técnico-táticas individuais, de grupo ou coletivas, visando criar desequilíbrios na defesa adversária e, consequentemente, permitir a finalização.

Já na categoria sub-13, observa-se que a incidência de finalizações a partir de Jogo Organizado foi significativamente inferior à categoria sub-17, e com tendência à inferioridade de valores para esta situação também em relação às categorias sub-15 e sub17. A principal estratégia para chegar à finalização foi a bola parada (laterais, escanteios e faltas). Ao relacionar-se este dado com o processo de ensino-aprendizagem treinamento, deve-se salientar que, apesar da finalização a partir de manobras ensaiadas de bola parada revelar-se como uma importante ferramenta para atingir o gol adversário, utilizá-la em demasia, com a redução do incentivo ao desenvolvimento do jogo posicional da equipe tende a revelar-se como inapropriada no desenvolvimento da capacidade tática dos atletas de futsal. Uma vez que a especificidade do jogo de futsal está relacionada à dependência de processos cognitivos por parte do jogador para reconhecer, orientar-se e regular as ações motoras. ${ }^{27}$ Insistir em manobras ensaiadas mecanizadas e pouco (ou nada) adaptáveis aos 
constrangimentos presentes nas situações observadas durante a realização de uma partida revela-se como uma opção que desfavorece a formação de atletas de futsal com capacidades táticas individuais e grupais adequadamente desenvolvidas, pelo interesse mediato do resultado.

Na principal fonte de finalizações na categoria sub-13, o lateral ofensivo, se evidenciou a exaustiva repetição da uma manobra ensaiada caracterizada pela presença de dois jogadores com o primeiro deles rolando a bola para o seu colega apenas suficiente para esta sair da linha lateral, enquanto o segundo corre em direção à bola para desferir o chute. Tal manobra, apesar da fácil compreensão pelos atletas, é facilmente marcável, com a simples presença de um defensor próximo. Sua constante repetição no jogo tende a minimizar os efeitos de facilitar a definição. Observou-se que esta situação é treinada para se obter a mecanização dos gestos (diferente da automatização, onde há a liberação de atenção para outros estímulos) por parte dos atletas, induz à pouca exercitação cognitiva durante a execução (tanto em situações de treino quanto nos jogos).

Considera-se que o processo de ensino-aprendizagem- treinamento no futsal, tanto para o jogo posicional quanto para bolas paradas, deve permitir não só que o atleta repita sempre os mesmos movimentos, mas sim que o mesmo seja capaz de detectar sinais são importantes que facilitem sua decisão, bem como levem ao conhecimento da provável ordem de aparição desses sinais relevantes dentro da ação esportiva. ${ }^{28}$

No estudo, observou-se que as bolas roubadas foram, apenas na categoria sub-13, categorizadas na segunda posição com o maior número incidência de finalizações. Este dado corrobora com a necessidade de repensar-se, para esta categoria, o processo de ensino-aprendizagem-treinamento. A opção por finalizar frequentemente através de bolas paradas associado ao alto número de finalizações a partir de bolas perdidas para esta categoria revela a dificuldade das equipes em conseguir criar desequilíbrios no sistema defensivo adversário com a bola rolando, ou seja, pouco desenvolvimento do jogo posicional. Assim, tanto o jogo posicional (relacionado ao ataque a partir de situações de Jogo Organizado e contra-ataque), quanto as manobras ensaiadas de bolas paradas (desde 
que abertas às variações ambientais e respostas criativas/inteligentes dos atletas), devem ser frequentemente estimulados por treinadores, mesmo nas categorias mais jovens, já que, dada a complexidade da dinâmica do jogo, aliada à alta velocidade e intensidade em que se desenrolam as ações, é necessário que os jogadores compreendam o jogo para melhor coordenarem as respostas motoras. ${ }^{27}$

Ainda acerca da situação das finalizações, observa-se que embora haja resultados de pesquisa apontando para alta incidência de contra-ataques em jogos de futsal $^{16 ; 20}$ a incidência de finalizações a partir de contra-ataques foi baixa nas quatro categorias, resultado consonante com o estudo de Marchi, ${ }^{21}$ que encontraram baixos percentuais de aproveitamento (conversão em gols) dos contra-ataques. Tal resultado pode estar relacionado com uma pouca capacidade dos jogadores envolvidos no processo ofensivo em, a partir de situações de superioridade numérica ofensiva (comuns em contra-ataques), na qual ocorre menos roubada de bola em comparação a situações com igualdade ou superioridade numérica defensiva, ${ }^{29}$ criar reais possibilidades de finalização. Desta forma, cabe ao treinador estimular situações para o aprendizado de princípios relacionados à situação de contra-ataque, permitindo que os atacantes percebam sinais relevantes para se oferecer, orientar, reconhecer espaços, sincronizar os movimentos e identificar linhas de passe de maneira a criar condições ideais para a finalização.

No que concerne ao setor de finalização, observam-se estratégias diferentes entre as categorias sub-20 e sub-13. Enquanto no sub-13 há um grande volume de finalizações a partir das regiões 4 e 6 , locais onde anteriormente citadas manobras ensaiadas de lateral mais tendem a ocorrer, as equipes da categoria sub-20 finalizaram mais a partir da região 5 e das três regiões mais próximas ao gol (1, 2 e 3), resultado em consonância com outros estudos. ${ }^{30}$ Como a equipe sub-20 apresentou maior correlação entre finalizações e gols em comparação à categoria sub-13, acredita-se que a estratégia de finalizar a partir da intermediária lateral ( 4 e 6 ) pode revelar-se como menos eficiente do que finalizar em regiões mais próximas ao gol (1, 2 e 3$)$ e no centro da quadra, com maior ângulo de chute (setor 5). O problema consiste em que, para conseguir progredir com a posse de bola na quadra, e criar possibilidades de finalização em regiões mais próximas ao gol, demanda-se 
um jogo posicional qualificado ou seja combinações entre dois-três jogadores, recorrendo a ações táticas de grupo, condição esta limitada em equipes que valorizem excessivamente o jogo individual e os lances de bola parada em detrimento de estratégias de Jogo Organizado.

Em relação ao local onde ocorreram as finalizações, com o aumento na idade dos atletas observa-se uma tendência de menor utilização dos setores 4 e 6 , correspondentes às laterais da quadra na região intermediária ofensiva. Encontraram-se diferenças significativas nos dois setores do sub-13 para: sub-15 e sub-20 (setor 4) e sub-17 e sub-20 (setor 6). Estes setores, apresentam reduzido ângulo para o chute a gol comparativamente às regiões centrais da quadra, e também estão distantes da baliza em comparação aos três setores próximos à linha de fundo do ataque. Isto leva a uma baixa eficiência nas finalizações. Além disso, por se tratar da beirada da quadra, a possibilidade de dobras na marcação e o limite físico da linha lateral tendem a criar maiores dificuldades para a realização de boas finalizações. Assim, torna-se importante para os treinadores da categoria sub-13 repensarem a estratégia de privilegiar finalizações a partir destes setores - principalmente em situações de lateral ofensivo - e criarem condições para que, a partir de situações de Jogo Organizado com manutenção da posse de bola, movimentação dos atletas sem bola, permitam a organização de ataques envolventes, conduzindo à finalização livre de marcação e obtendo, assim, maior eficiência no processo ofensivo.

Em relação ao resultado das finalizações, observa-se que, para todas as categorias, os resultados "rebatida pela defesa" e "fora" foram os indicadores que apresentaram maiores índices de repetição. Contudo, há um valor significativamente maior no número de bolas rebatidas pela defesa na categoria sub-13. No caso desta categoria, a utilização abundante de manobras ensaiadas principalmente em bolas paradas, notavelmente a partir de cobranças de lateral e elaboradas a partir de situações pouco complexas e mecanizadas, e o grande volume de bolas interceptadas pela defesa antes de chegarem ao gol reforça a hipótese de que a repetição de manobras ensaiadas de lateral, quando estas revelam-se mecanizadas e pouco complexas apresenta-se como uma estratégia facilmente detectável e, consequentemente, marcável pelo sistema defensivo adversário, como destacado 
anteriormente. Além disso, a mecanização das jogadas de bola parada limita o comportamento criativo do jogador e sua capacidade de "leitura" do jogo, pontos primordiais no jogo ofensivo e que não devem ser sacrificados em prol de uma estratégia excessivamente rígida. ${ }^{28}$

Desta forma, sugere-se que, com o intuito de dificultar a interceptação de bolas pelo sistema defensivo adversário e, consequentemente, aumentar as chances de gol, elaboremse manobras ensaiadas para as jogadas de lateral, conforme anteriormente citado, que permitam aos atacantes adaptá-las às características do adversário $^{31}$ e às diferentes respostas dos defensores, o que novas estratégias sejam traçadas no momento da ação e sejam obtidos melhores resultados. Assim, o movimento preestabelecido deve ser rico em soluções, já que se há uma única solução e a jogada não se desenvolve conforme planejado, o final pretendido - que se relaciona com a finalização ao gol - também não será alcançado. $^{28}$

Ampliando para as demais categorias, fica evidente que, apesar do grande número de finalizações a partir de situações de Jogo Organizado, devido ao número excessivo de finalizações sendo bloqueadas pelo sistema defensivo adversário antes de chegar ao gol, é necessário que as ações ofensivas conduzam a desequilíbrios defensivos no adversário, mais contundentes, o que possibilitaria mais finalizações com atacantes desmarcados ou com defensores em desvantagem temporal para impedir o chute. Assim, também para as demais categorias, elaborar estratégias de jogo que sejam ao mesmo tempo claras para os atletas, mas também permitam a alteração constante nos planos de ação a partir da percepção de sinais relevantes e antecipação de comportamentos dos adversários tende a criar condições para finalizações em situações mais clara de gol, o que reduz a capacidade da defesa de interceptar/bloquear um chute ao gol e, consequentemente, aumenta a eficiência nas finalizações.

Em relação à marcação de gols, relata-se maior efetividade nas finalizações na categoria sub-15 em comparação à sub-20, ${ }^{17}$ resultado contrário ao presente estudo. Observa-se que as categorias sub-13 e sub-20 apresentaram, como resultado da ação, números Conexões: revista da Faculdade de Educação Física da UNICAMP, Campinas, v. 11, n. 4, p. 24-44, out./dez. 2013. 
significativamente maiores de gols. Contudo, há diferença significativa entre o total de finalizações entre as categorias sub-13 (maior valor) e sub-20 (menor valor). Este dado revela que, na categoria sub-20, apesar da evolução técnica e tática dos atletas e dos sistemas defensivos adversários, há uma maior eficiência, na medida em que é necessário um menor número de finalizações para atingir-se o mesmo número de gols do que a categoria sub-13. Desta forma, reitera-se a impressão de que a condução do processo de ensino-aprendizagem-treinamento na categoria sub-13 deve ser revisto de forma a permitir aos atletas um jogo posicional qualificado e, consequentemente, amplie o acervo de ações técnico-táticas a serem utilizadas pelos atletas para a obtenção de chances de finalização.

\section{CONCLUSÃO}

Em relação à situação de finalização, o Jogo Organizado representou, para as categorias sub-15, sub-17 e sub-20, a principal estratégia para as equipes conseguirem finalizar ao gol adversário. Observou-se também que, na categoria sub-13, a utilização de bolas paradas, notavelmente o lateral ofensivo, revelou-se como uma importante estratégia para a criação de finalizações, embora não tenha sido encontrada correlação baixa, para esta categoria, entre a frequência de finalização e a frequência de gols. Estes resultados revelam a necessidade de readequação do processo de ensino-aprendizagem-treinamento pensado para a categoria sub-13, na medida em que o favorecimento da repetição, por vezes mecanizada, de manobras ensaiadas de lateral, pode conduzir ao empobrecimento do jogo posicional e, consequentemente, representar um déficit na formação dos atletas de futsal.

Observou-se também que as regiões mais próximas ao gol, demarcadas neste estudo pelos setores $1,2,3$, e a região central da intermediária ofensiva - setor 5 - revelaram-se importantes para a realização de finalizações nas categorias mais velhas, ao passo que os setores laterais na intermediária ofensiva - 4 e 6 - foram ao lado do setor 5, as mais utilizadas pelos atletas da categoria sub-13. Contudo, a baixa eficiência da categoria sub13, comparativamente à categoria sub-20, revelou que esta estratégia pode não ser a mais ideal para a concretização de gols. Assim, sugere-se que o processo de ensinoaprendizagem-treinamento seja pensado, pelos treinadores das equipes na categoria sub-13, de forma a permitir a diversificação das situações ofensivas, além de ser capaz de aumentar o conhecimento tático dos atletas, auxiliando-os na resolução de situações-problema 
durante o jogo e, consequentemente, permitindo que a equipe avance com a posse de bola até regiões com maior possibilidade de gols.

Por fim, acredita-se que estudos relativos à analise da performance no futsal estimulados com o intuito de subsidiar o trabalho de treinadores com dados para a adequação das propostas de ensino. Além disso, sugere-se a expansão de pesquisas de análise da performance para situações de treino, permitindo que treinadores tenham conhecimento acerca da proficiência com que os jogadores e a equipe realizam diferentes tarefas e assim aferir a congruência da sua prestação em relação aos modelos de jogo e treino preconizados. $^{8}$

\section{REFERÊNCIAS}

${ }^{1}$ SILVA, M. V.; GRECO, P. J. A influência dos métodos de ensino-aprendizagemtreinamento no desenvolvimento da inteligência e criatividade tática em atletas de futsal. Revista Brasileira de Educação Física e Esporte, São Paulo, v. 23, 2009.

${ }^{2}$ SILVA, M. V. et al. Estratégia e tática no futsal: uma análise crítica. Caderno de Educação Física, Marechal Candido Rondon, v. 10, 2011.

${ }^{3}$ MULLER, E. S. Comportamentos táticos no futsal: estudo comparativo referente a escalões de formação e ao futebol. 2010. Dissertação (Mestrado em Ciência do Desporto) Faculdade de Ciências do Desporto e de Educação Física, Universidade do Porto, Porto, 2010.

${ }^{4}$ GARGANTA, J. M. Modelação tática do jogo de futebol: estudo da organização da fase ofensiva em equipas de alto rendimento. 1997. Tese (Doutorado em Ciência do Desporto) Faculdade de Ciências do Desporto e de Educação Física, Universidade do Porto, Porto, 1997.

${ }^{5}$ MICHELINI, M. C. et al. Futsal: tática defensiva contemporânea e a teoria de ensino dos jogos esportivos coletivos de Claude Bayer. Conexões, Campinas, v. 10, n.1, 2012. 
${ }^{6}$ ANGUERA, M. Observación en deporte y conducta cinésico-motriz: aplicaciones. Barcelona: Editora da Universidade de Barcelona, 1999.

${ }^{7}$ ARQILAGA, M. T. A. et al. La metodologia observacional en el deporte: conceptos básicos. Lecturas, Educación Física e Deportes, Buenos Aires, v. 5, 2000.

${ }^{8}$ GARGANTA, J. M. A análise da performance nos jogos desportivos: revisão acerca da análise do jogo. Revista Portuguesa de Ciências do Desporto, Porto, v. 1, 2001.

${ }^{9}$ TRAVASSOS, B. et al. Interpersonal coordination and ball dynamics in futsal (indoor football). Human Movement Science, Amsterdan, v. 30, 2011.

${ }^{10}$ BRAVO, L.; OLIVEIRA, M. T. Comportamentos táticos no jogo de futsal: os princípios do jogo. Millenium, Viseu, v. 42, 2012.

${ }^{11}$ MORENO, J. H. Fundamentos del esporte: analisis de las estruturas del juego deportivo. 1996. Dissertação (Mestrado em Educação Física). Universidade Estadual Paulista, Rio Claro, 1996.

${ }^{12}$ LAMAS, L.; NEGRETTI, L.; DE ROSE, J. D. A análise da tática ofensiva no basquetebol. In: DE ROSE, J. D.; TRICOLI, V. (Ed.). Basquetebol: uma visão integrada entre ciência e prática. Barueri: Manole, 2005.

${ }^{13}$ TAVARES, F. Análise da estrutura e dinâmica do jogo nos jogos desportivos. In: BARBANTI, J.; BENTO, J. et al (Ed.). Esporte e atividade física: interação entre rendimento e qualidade de vida. São Paulo: Manole, p. 129-143, 2002.

${ }^{14}$ LEITE, W. S. S. Analysis of the offensive process of the portuguese futsal team. Pamukkale Journal of Sport Sciences, Pamukkale, v. 3, 2012.

${ }^{15}$ MARCHIORI, C. L. Análise do chute ofensivo nos jogos universitários gaúchos de futsal 2011. 2011. Trabalho de Conclusão de Curso (Graduação em Educação Física) Faculdade de Educação Física, Universidade Federal do Rio Grande do Sul, Porto Alegre, 2011.

Conexões: revista da Faculdade de Educação Física da UNICAMP, Campinas, v. 11, n. 4, p. 24-44, out./dez. 2013. 
${ }^{16}$ SANTANA, W. C.; GARCIA, O. B. A incidência do contra-ataque em jogos de futsal de alto rendimento. Pensar a Prática, Goiânia, v. 10, 2007.

${ }^{17}$ CUNHA, G. A. et al. Análise das variáveis ataque e finalização da modalidade futsal: comparação entre as categorias sub-15 e adulta. Coleção Pesquisa em Educação Física, Jundiaí, v. 8, 2009.

\section{${ }^{18}$ MOREIRA, V. J. P. Processos metodológicos de ensino-aprendizagem-treinamento} no futsal. 2005. Dissertação (Mestrado em Educação Física) - Escola de Educação Física, Fisioterapia e Terapia Ocupacional, Universidade Federal de Minas Gerais, Belo Horizonte, 2005.

${ }^{19}$ SILVA, M.; AL, E. Ações ofensivas no futsal: uma comparação entre as situações de jogo organizado, de contra-ataque e de bola parada. Revista Portuguesa de Ciências do Desporto, Porto, v. 4, 2004.

${ }^{20}$ IROKAWA, G. N. F. et al. Caracterização das circunstâncias e setores de finalização do jogo de futsal: um estudo da fase final da Copa do Mundo de Futsal FIFA-2008. Lecturas, Educación Física y Deportes, Buenos Aires, v. 15, 2008.

${ }^{21}$ MARCHI, R. V. et al. Incidência de gols resultantes de contra-ataques de equipes de futsal. Conexões, Campinas, v. 8, n. 3, p. 16-22, 2010.

${ }^{22}$ BRAZ, J. Organização do jogo e do treino em futsal: estudo comparativo acerca das concepções de treinadores de equipas de rendimento superior de Portugal, Espanha e Brasil. 2006. Dissertação (Mestrado em Ciência do Desporto) - Faculdade de Ciências do Desporto e de Educação Física, Universidade do Porto, Porto, 2006.

${ }^{23}$ OLIVEIRA, R. F. et al. The bidirectional links between decision making, perception and action. Progress in Brain Research, Amsterdam, v. 174, 2009.

${ }^{24}$ NITSCH, J. Ecological approaches to sport activity: a commentary from a actiontheoretical point of view. International Journal of Sports Psychology, Rome, v. 40, 2009.

Conexões: revista da Faculdade de Educação Física da UNICAMP, Campinas, v. 11, n. 4, p. 24-44, out./dez. 2013. 
${ }^{25}$ GARGANTA, J. M. Competências no ensino e treino de jovens futebolistas. Lecturas, Educación Física e Deportes, Buenos Aires, v. 8, 2002.

${ }^{26}$ GRECO, P. J.; BENDA, R. N. Iniciação esportiva universal. Belo Horizonte: Editora da Universidade Federal de Minas Gerais, 1998.

${ }^{27}$ SOUZA, P. R. C. Validação de teste para avaliar a capacidade de tomada de decisão e o conhecimento declarativo em situações de ataque no futsal. 2002. Dissertação (Mestrado em Educação Física) - Escola de Educação Física, Fisioterapia e Terapia Ocupacional, Universidade Federal de Minas Gerais, Belo Horizonte, 2002.

${ }^{28}$ TEJADA, J. V.; PEÑAS, J. L. Entrenamiento de base en fútbol sala. Badalona: Paidotrbo, 2003.

${ }^{29}$ MIRANDA, C. Defesa zona pressing enquanto sistema defensivo precursor do aumeno de finalizações - estudo de jogos finais da Taça UEFA e Liga dos Campeões. 2005. Trabalho de Conclusão de Curso (Licenciatura em Ciência do Desporto) - Faculdade de Ciências do Desporto e de Educação Física, Universidade do Porto, Porto, 2005.

${ }^{30}$ PESSOA, V. L. et al. Análise dos gols da Liga Futsal 2008. Lecturas, Educación Física y Desportes, Buenos Aires, v. 13, 2009.

${ }^{31}$ SAMPEDRO, J. Futbol sala: análisis metodológico de los sistemas de juego. Madrid: Gymnos Editorial Deportiva, 1997.

Recebido em: 30 out. 2013 Aceito em: 15 dez. 2013 Contato: Gibson Moreira Praça gibson_moreira@yahoo.com.br 